\title{
From Toronto to East Africa: a medical library partnership
}

\author{
Sandra Kendall
}

In 2008, I had the opportunity to go to Ethiopia (Fig. 1) to assess current medical library resources and services provided at the Black Lion Hospital, which is the major teaching hospital for Addis Ababa University (AAU), Addis Ababa, Ethiopia. I attended the Addis Ababa International Educational Symposium, Addis Ababa, Ethiopia, where the Ethiopian Ministry of Education put forth the desired and ambitious goal of increasing Ph.D. graduates in all disciplines by 5000 and Masters graduates by 10000 within the next 10 years (medical subspecialists are included with Ph.D.s under this requirement).

Universities worldwide with an interest in educational partnerships were invited to this symposium in order to help AAU meet its goal of dramatically increasing its number of academics. My invitation came from Dr. Clare Pain from the University of Toronto's Wilson Centre, Toronto. Dr. Pain is the Toronto-based lead and Dr. Atalay Alem is the Ethiopian-based lead for the Toronto Addis Ababa Psychiatry Partnership (TAAPP, www.utoronto.ca/ethiopia) (Fig. 2). For the last 7 years TAAPP has provided training at AAU for psychiatry residents, in the first, and currently the only, psychiatry training program in the country. The partnership between AAU and Emmanuel Psychiatry Hospital, Addis Ababa, Ethiopia (www.utoronto.ca/ethiopia), has included generous assistance from Mount Sinai Hospital's Psychiatry Department, Toronto; The Peter A. Silverman Centre for International Health, Mount Sinai Hospital; and the University of Toronto's Wilson Centre and Department of Psychiatry. TAAPP has laid the ground work and created the founding principles for the partnership developed for the advancement of medical library services.

In 2003, Ethiopia had 11 foreign-trained psychiatrists out of a total of 1800 physicians in a country with a population greater than 77 million. This translates roughly into a ratio of 1 physician per 42000 patients. In comparison, according to Statistics Canada 2009, Canada has approximately 60000 physicians for a population of approximately 32 million. Canada's physician to patient ratio is approximately 1 physician per 533 patients.

Today there are 39 practicing psychiatrists in Ethiopia and a thriving psychiatric residency program with approximately six new residents graduating every year.
The previously mentioned success of TAAPP has now transformed and expanded into over a dozen programs including library science, internal medicine, paediatrics rehabilitation medicine, nursing, emergency medicine, etc. This new group of disciplines is organized under a collaboration called the Toronto Addis Ababa Academic Collaboration (TAAAC, www.taaac.ca).

To increase Ph.D. graduates and subspecialists in medicine, it is a priority to further develop medical library services throughout Ethiopia.

My attendance at the 2008 Addis Ababa International Educational Symposium was an opportunity to assess current Ethiopian medical library services. This initial assessment has led to a multi-year library-to-library partnership between the University of Toronto's fully affiliated teaching hospital, Mount Sinai, and the AAU's Central Medical Library at the Black Lion Hospital. The partnership agreement developed at this symposium between the Chief Medical Librarian and myself is posted at www.TAAAC.ca under the Programs tab, under Library Services.

Our partnership addresses three goals to further develop medical library services and training in Ethiopia:

- The first goal, identified by the Chief Medical Librarian of the Black Lion Hospital, Petros Demilew, was to improve the print book collection at the Central Medical Library. To address this, we established a "collection development outline" and for the past 2 years, any TAAAC member going to Ethiopia has been obligated to deliver a donated textbook that meets the criteria of the "collection development outline, to the Black Lion Hospital. Our first overseas shipment of donated medical books was sent in August 2010. The hospital library community has also been invited to donate reasonably current discards to the University of Toronto's, student-volunteer-operated Books with Wings project. Login Canada and Toronto Notes continue to be strong supporters of this campaign. At the time of this writing (June 2010) I am unable to report how many books were delivered, but as we are able to send larger shipments I will detail our successes.

- Our second goal was to address a number of technological barriers in Ethiopia regarding library resources. For

S. Kendall. Global Health Scholar, The Peter A. Silverman Centre for International Health, General Member Wilson Centre, University of Toronto, Director Library Services, Mount Sinai Hospital, Joseph and Wolf Lebovic Health Complex, 600 University Avenue Suite 18-234, Toronto, ON M5G 1X5, Canada (e-mail: skendall@mtsinai.on.ca). 
Fig. 1. A scenic view of Ethiopia.

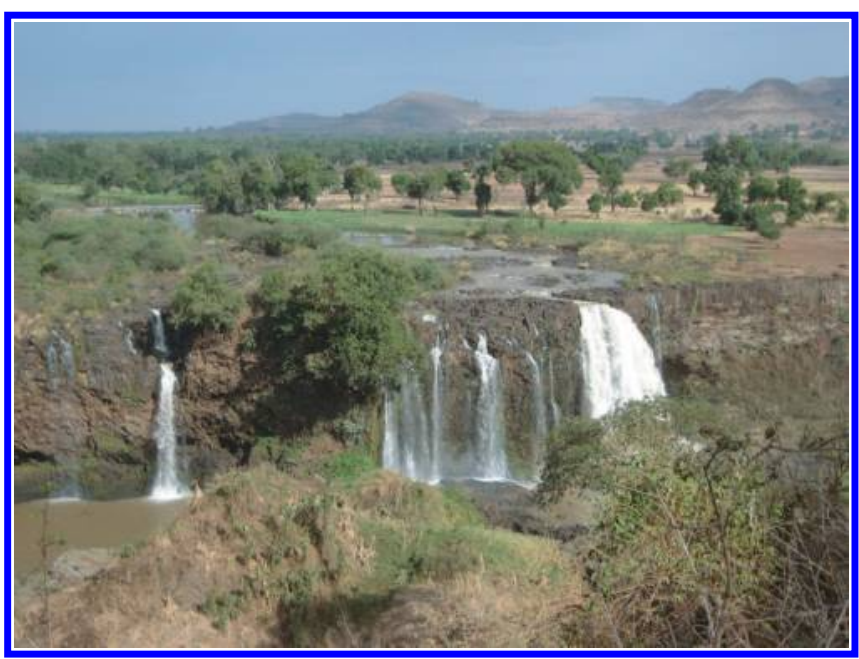

instance, slow bandwidth restricts the ability to download medical journal articles or e-mail daily. Also, private internet providers can make it hard to negotiate electronic access. A number of solutions are being pursued. Our partnership with Dr. Andrew Howard, Office of International Surgery, Sick Children's Hospital, Toronto, one of the founders of the Ptolemy Project, has led to the redesign of the pre-existing Ptolemy library navigation page. This redesign was intended to speed up the navigation process to the most relevant full-text resources available to the developing country. East African surgeons must register for the Ptolemy project library's electronic resources as Ptolemy is the gateway for these surgeons to access the University of Toronto Libraries' resources. We have negotiated access to drug information, EBSCO's Dynamed, and UpToDate through Ptolemy. These clinical decision support resources provide quick, concise, electronic, and mobile access that improves patient care. I am very proud to have had the opportunity to work with these vendors to make such an impact on a developing country such as Ethiopia.

- Our third goal focused on clinical librarian skills training and knowledge transfer to Ethiopian medical librarians. This began with training with Mr. Petros Demilew and myself.

Petros Demilew was awarded the prestigious 2010 Medical Library Association's Cunningham Fellowship and it could not have come at a better time, furthering his knowledge of medical libraries, evidence-based practice, and clinical librarianship. After Petros spent time as part of the Fellowship at Yale University and George Washington University, we both had the opportunity to work together at the Medical Library Association in Washington D.C. to further the goals of our library partnership. Petros' attendance at the HINARI training, as one who uses the resources provided by the World Health Organization, clarified how valuable products such as Dynamed and UpToDate are in low

Fig. 2. University of Toronto team with their Ethiopian counterparts.

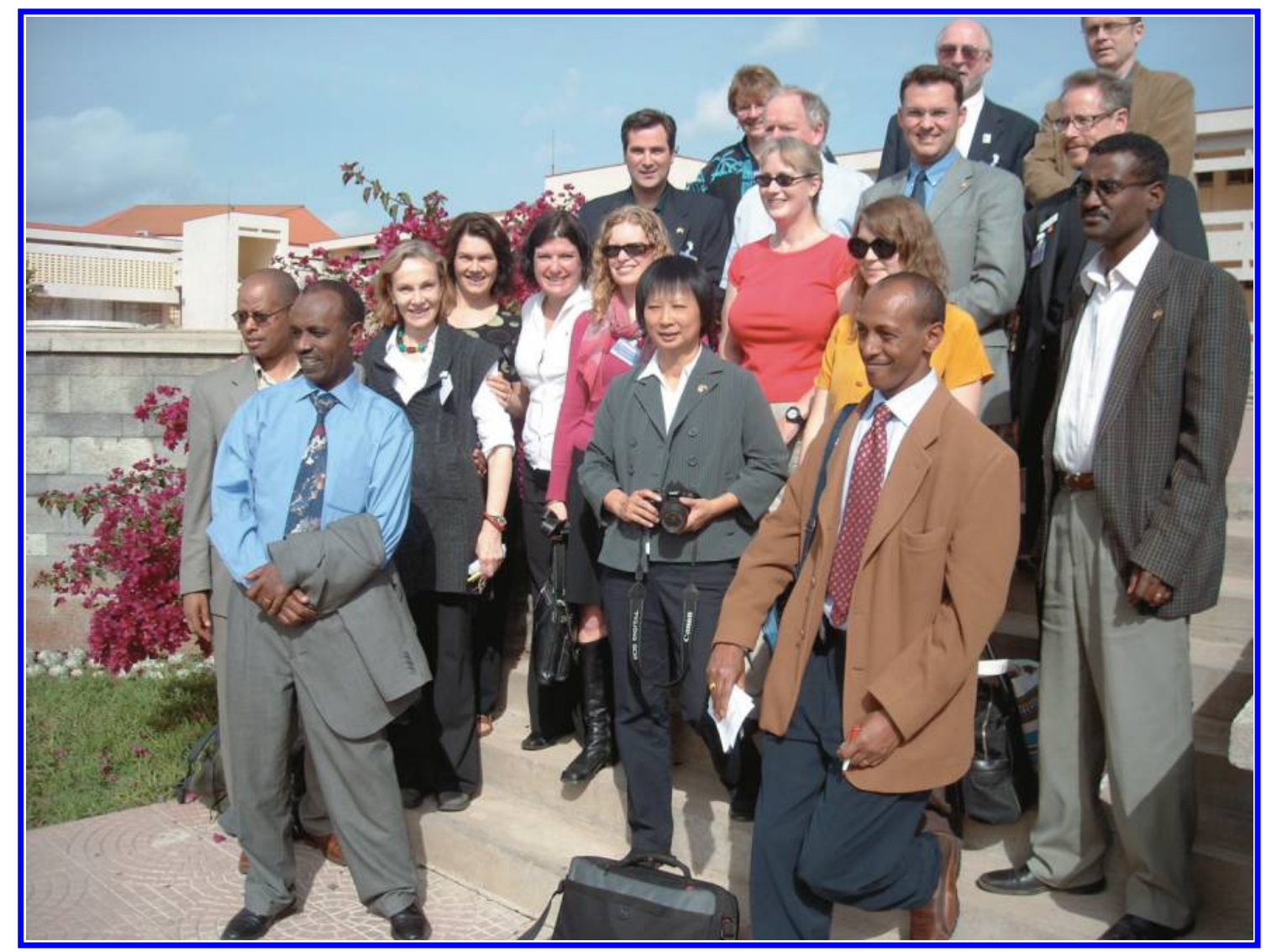


Fig. 3. Person meditating.

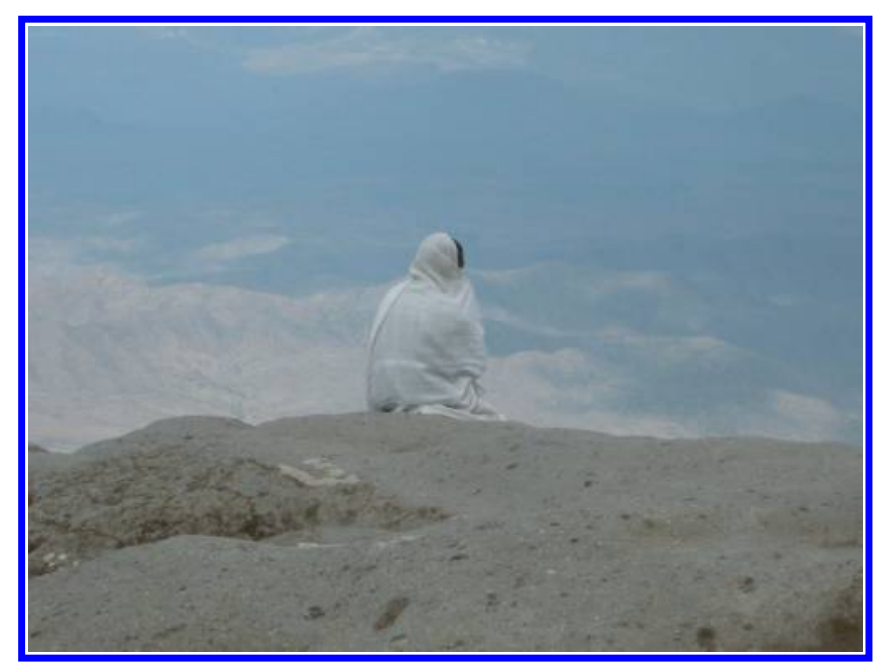

income countries due to their content and rapid ease of use. It is clear that Ptolemy provides access to resources that are not available elsewhere but are critical for Ethiopian researchers, specialists, and subspecialists.

Our next steps: Petros has shown me plans for a new building for the Central Medical Library. Nursing, medicine, and all allied health disciplines will have resources and access to this multilevel facility. To further support and develop medical libraries in Ethiopia, we are planning to have a qualified group of medical librarians provide training for librarians in Ethiopia on medical and clinical librarianship. Sessions will be offered to medical and nursing students as well. It is anticipated that this initial training will lead to health sciences library courses being introduced into the library program at the University.

If you are interested in helping please let me know!

For more information on working as part of the global community and for references to sites or projects mentioned in this article, please read any of the following references:

Beveridge M, Howard A, Burton K, Holder W. The Ptolemy project: a scalable model for delivering health information in Africa. BMJ. 2003 Oct 4;327(7418):790-3.

Kidder T. Mountains beyond mountains: the quest of Dr. Paul Farmer, a man who would cure the world. Random House: New York; 2004.

Singer P. The life you can save: acting now to end world poverty. Random House: New York; 2009.

Strangway D. Knowledge will empower Africa. Toronto Star, 2010 June 23; A23.

Toronto Addis Ababa Psychiatry Project (TAAPP) www. utoronto.ca/ethiopia

Toronto Addis Ababa Academic Collaboration (TAAAC) www.TAAAC.ca 